\title{
Is Bilateral Ureterorenoscopy the First Choice for the Treatment of Bilateral Ureteral Stones? An Updated Study
}

\author{
Bulent Gunlusoy Tansu Degirmenci Murat Arslan Zafer Kozacıoglu \\ Omer Koras Yasin Ceylan Bumin Ors \\ Department of Urology, Izmir Education and Research Hospital, Izmir, Turkey
}

\section{Key Words}

Bilateral • Ureteral stones • Ureterorenoscopy • Pneumatic lithotripsy

\begin{abstract}
Introduction: We analyze our recent results and discuss the advantages and disadvantages of bilateral single-session ureterorenoscopy (URS) for bilateral ureteral stones. Patients and Methods: 55 patients underwent URS with pneumatic lithotripsy (PL) for bilateral stones. 61 (55.5\%), 28 (25.4\%) and 21 (19.1\%) stones were located in the lower, middle and upper ureter, respectively. Results: Of the 110 stones, 99 (90.0\%) were fragmented in a single procedure. The stone clearance rate was $94.5 \%$ after the second session. The stone clearance rates with regard to stone location were 71.4, 89.3 and $96.7 \%$ for the upper, middle and lower ureter, respectively. An analysis of the clearance rates based on location demonstrated that lower ureteric stones were more successfully removed than upper ureteric stones (96.7 vs.71.4\%, $p=$ 0.003). Conclusion: Bilateral single-session URS with PL is a highly effective treatment modality for bilateral ureteral stones. The success rate of PL is affected by stone size and location.

Copyright $\odot 2012$ S. Karger AG, Basel
\end{abstract}

\section{Introduction}

Ureterorenoscopy (URS) is a minimally invasive method for the treatment of ureteral stones. Current urological approaches to stone disease have shifted from treating symptomatic stones to searching for ways to render patients stone-free while minimizing interventionrelated morbidity [1]. URS has been approved for treating lower ureteral stones, but significant advances in ureterorenoscope design combined with the introduction of new lithotripsy techniques for intracorporeal stone fragmentation have led to the treatment of proximal stones in a manner that has similar efficacy and safety levels as techniques performed for distal calculi [2-4]. Bilateral URS for bilateral ureteral stones is rarely indicated in a single session. The possibility of serious complications, such as bilateral injuries, may prevent even the most experienced surgeons from attempting the procedure [5]. However, this technique is ideal for treating the patient faster than any other procedure and rendering the patient stone-free after a single intervention without complications.

In this study, we analyze our recent results and discuss the advantages and disadvantages of bilateral single-session URS for bilateral ureteral stones.

\section{KARGER}

Fax +41613061234

E-Mail karger@karger.ch

www.karger.com
(C) 2012 S. Karger AG, Basel

0042-1138/12/0894-0412\$38.00/0

Accessible online at:

www.karger.com/uin
Bulent Gunlusoy

1828/6 sokak No: 48/1 Karsiyaka

TR-35100 Izmir (Turkey)

E-Mail bulentgunlusoy@hotmail.com 
Table 1. Patient characteristics

\begin{tabular}{lc}
\hline Patients & 55 \\
Male/female & $37 / 18$ \\
Mean age, years & $46.1 \pm 13.9$ (range 22-81) \\
Stone location & \\
$\quad$ Upper ureter & $19.1 \%(\mathrm{n}=21)$ \\
$\quad$ Middle ureter & $25.4 \%(\mathrm{n}=28)$ \\
$\quad$ Lower ureter & $55.5 \%(\mathrm{n}=61)$ \\
Stone size, mm & \\
$\quad$ & $11.9 \pm 3.8$ \\
$\quad$ Mpper ureter & $11.3 \pm 3.6$ \\
$\quad$ Lower ureter & $9.9 \pm 3.7$ \\
Dilatation & 45 \\
Preoperative creatinine & $1.2 \pm 1.1$ (range 0.7-6.2) \\
Preoperative failed ESWL & 11 \\
Mean stone size, mm & $10.7 \pm 4.2$ (range 5-21) \\
Mean operation time, min & $59 \pm 21$ (range 21-100) \\
Mean hospitalization time, days & $2.4 \pm 0.9$ (range 1-5) \\
\hline
\end{tabular}

ESWL $=$ Extracorporeal shock wave lithotripsy.

Table 2. Success rate based on stone location and size

\begin{tabular}{lcl}
\hline & Stones & $\begin{array}{l}\text { Overall suc- } \\
\text { cess rate, \% }\end{array}$ \\
\hline Upper ureter & $15 / 21$ & 71.4 \\
Middle ureter & $25 / 28$ & 89.3 \\
Lower ureter & $59 / 61$ & 96.7 \\
\hline Size $\leq 10 \mathrm{~mm}$ & $70 / 73$ & 95.9 \\
Size $>10 \mathrm{~mm}$ & $29 / 37$ & 78.4 \\
\hline Initial stone-free rate & $99 / 110$ & 90.0 \\
Second-session URS stone-free rate & $104 / 110$ & 94.5 \\
\hline
\end{tabular}

\section{Patients and Methods}

Between February 2001 and June 2010, 89 patients underwent bilateral same-session URS for different reasons, such as bilateral ureteral stones, determining the etiology of bilateral hydronephrosis, atypical urine cytology in recurrent microscopic hematuria or ureteral strictures. Bilateral URS with pneumatic lithotripsy (PL) was performed for 62 of these patients with bilateral stones. Of these patients, 7 patients who had previously been stented or had nephrostomy tubes were excluded from the study to better evaluate the passing of the ureterorenoscope and postoperative stone passage. Routine blood and urine tests were performed preoperatively. To localize the stone and assess renal function, excretory urography was performed. Noncontrast computerized tomography (NCCT) was performed for patients with serum creatinine levels greater than $1.6 \mathrm{mg} / \mathrm{dl}$ who were suspected as having nonopaque stones and had a history of allergic reaction to intravenous contrast medium. Stone size was assessed by measuring its maximal diameter on IVP or NCCT.

Is Bilateral Ureterorenoscopy the First Choice?
61 (55.5\%), 28 (25.4\%) and 21 (19.1\%) stones were located in the lower, middle and upper ureter, respectively. 73 (66.4\%) stones were less than or equal to $10 \mathrm{~mm}$ in diameter, and 37 (33.6\%) stones were larger than $10 \mathrm{~mm}$. PL was performed with 8 -Fr or 10 -Fr semirigid ureterorenoscopes under general or regional anesthesia. The orifice was dilated with olive-tipped bougie dilators when needed (not routine). Large fragments were removed with forceps, while small fragments were left for spontaneous passage. At the end of the procedure, a 5-Fr ureteral catheter was placed and removed either $24 \mathrm{~h}$ after the operation in noncomplicated procedures or 48-72 $\mathrm{h}$ after the operation in complicated cases. A double-J stent was inserted to address residual fragments or for stones that migrated to the kidney. The decision to remove the double-J stent was made by the surgeon after radiologic examination. Follow-up studies included a kidney ureter bladder (KUB) film obtained with an ultrasound within $24 \mathrm{~h}$ postoperatively and 6 weeks after the operation.

Intravenous urography was performed in cases with pelvicalyceal dilatation. Stone-free status was defined as the absence of any residual stones on a KUB film after 6 weeks. If residual stones were present, a second session of URS was performed. Intraoperative and postoperative complications associated with singlesession bilateral URS were recorded and reported according to the modified Clavien grading system [6].

The SPSS 11.0 statistical program was used for the statistical analyses. The means and the standard deviations of the stone sizes were calculated for successful and unsuccessful groups. The Mann-Whitney U test was used to compare the stone sizes of the 2 groups. The clearance rates were compared based on the different localization using Fisher's exact test. Values of $p<0.05$ were accepted as statistically significant.

\section{Results}

The patients' characteristics are shown in table 1 . There were 37 (67.3\%) male and 18 (32.7\%) female patients with a mean age of $46.1 \pm 13.9$ years $(22-81)$. The mean stone size was $10.7 \pm 4.2 \mathrm{~mm}(5-21)$, and the mean operation time was $59 \pm 21 \mathrm{~min}(21-100)$. Of the 110 stones, $99(90.0 \%)$ stones were fragmented in a single procedure. The mean stone sizes ( \pm SDs) for the successful and unsuccessful groups were $10.1 \pm 3.5$ and $12.9 \pm$ 3.1, respectively, and this difference was statistically significant ( $\mathrm{p}=0.008)$. The initial stone-free rate after URS was $95.9 \%(70 / 73)$ for patients with calculi less than or equal to $10 \mathrm{~mm}$ and $78.4 \%(29 / 37)$ for those patients with calculi larger than $10 \mathrm{~mm}(\mathrm{p}<0.006)$. The stone clearance rate was $94.5 \%$ after the second session of URS. Success rates with regard to stone location and size are shown in table 2. Comparing the three different locations, as shown in table 3 , indicated that the procedure was more successful for lower ureteric stones than for upper ureteric stones (96.7 vs. $71.4 \%$, respectively, OR $11.8,95 \%$ CI $2.2-64.9, \mathrm{p}=0.003)$. With respect to the 
stone sizes (table 4), the procedures for stones that were $10 \mathrm{~mm}$ or smaller were significantly more successful than procedures performed for stones larger than $10 \mathrm{~mm}$ (95.9 vs. 78.4\%, respectively, OR 6.4, 95\% CI 1.5-25.9, $\mathrm{p}=0.006)$.

Bilateral ureteral catheters were placed postoperatively after PL in 92 units, and bilateral double-J stents were placed in 4 units. The double-J stents were removed between 2 and 6 weeks after the operation. A second session of URS was performed for 5 stones after an unsuccessful URS. Three stones were sent to shock wave lithotripsy (SWL). Percutaneous nephrolithotripsy was performed for three migrated stones with concomitantly treated renal stones. To determine whether the stone had migrated or was a concomitant renal stone, the preoperative and the postoperative KUB images were compared. Those stones with the same location or configuration on both films were regarded as concomitant stones, while those stones that appeared as a new opacification on the postoperative KUB film were regarded as migrated stones. After the secondary procedure, all patients were free of stones.

Postoperative complications were mainly minor, consisting of postoperative fever in $5(9.1 \%)$ patients, urinary tract infections (UTIs) in 3 (5.4\%) patients, urosepsis in $1(1.8 \%)$ patient, small mucosal laceration without leak in $4(7.3 \%)$ patients, hematuria in $3(5.4 \%)$ patients and stone migration in 4 (7.3\%) ureters; these complications were categorized as grade I, II, IIIa and IVb in 5, 3, 7 and 1 patient, respectively, based on the modified Clavien classification of surgical complications. Urinary tract infection was treated with culturespecific antibiotics and antipyretics. One patient with urosepsis was hospitalized and treated with intravenous antibiotics, analgesics and fluid support. For hematuria, conservative management with forced diuresis and increased fluid intake was effective. Four migrated stones were treated by double-J stent insertion and further with SWL. There were no major or long-term complications such as ureteral perforation and stricture. Hospitalization time ranged from 1 to 5 days with an average of $2.4 \pm 0.9$ days.

\section{Discussion}

Accomplishing stone-free status increases the time to stone recurrence and the risk of subsequent symptomatic stone episodes [7]. Many factors affect the success rates of stone treatment, including stone size, composition, loca-
Table 3. Comparison of success rates based on location

\begin{tabular}{lllll}
\hline Location & \multicolumn{2}{l}{ Results } & & \\
\cline { 2 - 5 } & unsuccessful & successful & total & $\mathrm{p}$ \\
\hline Lower & $2(3.3 \%)$ & $59(96.7 \%)$ & 61 & $0.320^{*}$ \\
Middle & $3(10.7 \%)$ & $25(89.3 \%)$ & 28 & \\
Total & $5(5.6 \%)$ & $84(94.4 \%)$ & 89 & \\
\hline Lower & $2(3.3 \%)$ & $59(96.7 \%)$ & 61 & $0.003^{*}$ \\
Upper & $6(28.6 \%)$ & $15(71.4 \%)$ & 21 & \\
Total & $8(9.8 \%)$ & $74(90.2 \%)$ & 82 & \\
\hline Middle & $3(10.7 \%)$ & $25(89.3 \%)$ & 28 & $0.146^{*}$ \\
Upper & $6(28.6 \%)$ & $15(71.4 \%)$ & 21 & \\
Total & $9(18.4 \%)$ & $40(81.6 \%)$ & 49 & \\
\hline
\end{tabular}

* Fisher's exact test.

Table 4. Success rates based on a cut-off value of $10 \mathrm{~mm}$

\begin{tabular}{lllll}
\hline Size & Results & & & \\
\cline { 2 - 5 } & unsuccessful & successful & total & $\mathrm{p}$ \\
\hline$\leq 10 \mathrm{~mm}$ & $3(4.1 \%)$ & $70(95.9 \%)$ & 73 & $0.006^{*}$ \\
$>10 \mathrm{~mm}$ & $8(21.6 \%)$ & $29(78.4 \%)$ & 37 & \\
\hline Total & $11(10.0 \%)$ & $99(90.0 \%)$ & 110 & \\
\hline
\end{tabular}

* Fisher's exact test.

tion and different anatomical parameters [8]. Bilateral ureteral stones are an important risk factor even for an experienced endourologist. These stones can cause obstructive uropathy and subsequent deterioration of renal function, which requires immediate surgical intervention. It is very important to decompress the obstructed urinary tract either with a surgical intervention or a transient urinary diversion, such as percutaneous nephrostomy.

Ureterorenoscopic lithotripsy is our first-line approach for bilateral ureteral stones in any location. In our previous study with bilateral stones, the stones were successfully fragmented in $88.1 \%$ of patients after a single procedure and $93.1 \%$ of patients after the second session [9]. When active ureteral stone treatment is warranted, the best procedure to choose depends on several factors, including stone location and size, surgeon experience, patient preference, available equipment and cost 
effectiveness [10]. Although SWL is a reasonable firstline option for patients who are willing to accept a longer time to be stone-free or are unwilling to stay in the hospital to undergo general anesthesia, this technique is associated with high retreatment rates [11]. Some stones are difficult to fragment by SWL, and the fragments may remain in the urinary tract even after successful fragmentation of the stone [12]. SWL is efficacious for upper ureteral calculi with a diameter of less than $10 \mathrm{~mm}$ [13]. The overall stone-free rate is more than $80 \%$ when using SWL to treat proximal ureteral stones [14]. However, SWL has a low success rate for large stones. In two studies comparing SWL and URS lithotripsy for the management of large upper ureteral stones, the success rates were $61 \%$ and $63.6 \%$, respectively $[4,15]$. In a recent study, the safety and efficacy of URS was greater than SWL in the treatment of proximal ureteral stones $<20 \mathrm{~mm}$ with a low retreatment rate [16]. In another report, semirigid URS using PL for the treatment of stones $>30 \mathrm{~mm}$ was safe and highly efficacious, particularly in the distal ureter [17]. SWL is less successful for distal stones in the emergency setting [18]. In a previous study in which we discussed the effects of the ureteric location of the stones on the success rates, we showed that stones in different locations, including the proximal ureter, can be successfully treated with URS [19]. In the current study, the overall stone-free rate for bilateral stones was $90 \%$ after the first attempt and $94.5 \%$ after the second session of URS.

To assess postoperative stone clearance, KUB film was used in our series. KUB film has a limited sensitivity for the detection of urolithiasis, but the specificity is acceptable [20]. KUB film could be used for follow-up in $63 \%$ of cases [21]. All stones observed on NCCT were also visible on the KUB film, which has been the preferred modality for follow-up imaging if the stone was visible on the initial film. KUB film is considerably cheaper and quicker and exposes the patient to less radiation [22]. A routine KUB film obtained shortly after the operation to evaluate residual stones has become the standard management protocol in most clinics.

Another successful technique for the treatment of ureteral stones is flexible ureterorenoscopic (FURS) lithotripsy. A Ho:YAG laser can effectively fragment any stone regardless of composition or size and can reach the entire urinary tract because it can be deployed on rigid and flexible ureterorenoscopes [23]. Compared to other intracorporeal lithotripters, the holmium laser yields the smallest fragment size, with many fragments smaller than $1 \mathrm{~mm}$ [24]. The procedure results in minimal ureteral trauma and postoperative edema, and the smaller remaining fragments are likely to pass spontaneously [23]. Holmium laser lithotripsy using both semirigid and FURS lithotripsy is perhaps the standard of care over PL. In addition, in the case of stone migration, FURS can be used for further treatment. Unfortunately, the flexible device was not available in our hospital during the time period studied. Beginning 14 months ago, we have been successfully using FURS and semirigid URS together with a Ho:YAG laser. An important point that should not be overlooked in the selection of PL is that pneumatic energy is stronger and cheaper than the holmium laser [12]. Comparing these two techniques will be the subject of a future study in our clinic.

Another alternative approach in the management of these stones is to relieve the obstruction by the insertion of a nephrostomy tube or double-J stent and fragment the stone later by SWL. Insertion of a nephrostomy tube under local anesthesia is a better choice if there is evidence of sepsis at presentation [10]. However, this technique has some disadvantages, such as urine leakage, displacement of the nephrostomy tube and stoma maintenance. We inserted bilateral nephrostomy tubes into 3 patients with bilateral obstruction and 1 patient with urosepsis. Insertion of a double-J stent is another option. However, apart from complications such as ureteral perforation and failure to pass the stent, this stent may increase the risk of the urosepsis. The stent may cause edema of the ureteral wall, which may negatively affect the passage of fragments and successful fragmentation by reducing the shock-wave energy. The main advantage of URS is immediate decompression of the obstruction. Our hospitalization time ranges from 1 to 5 days. One patient with urosepsis was hospitalized postoperatively for a longer time than the others.

Bilateral URS has potential risks, which have been documented in many studies. Hollenbeck et al. [25] reported that bilateral URS carries an increased risk of postoperative morbidity in their series of 34 patients with bilateral ureteral calculi. They concluded that the risk is proportional to the number of renal units treated. Deliveliotis et al. [26] reported that one session of bilateral URS can be performed safely with a stone-free rate of $83.3 \%$. Camilleri et al. [5] found an $81 \%$ success rate, which was directly related to stone burden and location. Our study shows that URS displays a high success rate in lower ureteral stones (96.7\%). Patients with upper ureteral stones had the lowest stone-free rate (71.4\%). Patients with calculi larger than $10 \mathrm{~mm}(78.4 \%)$ also showed low success rates. 
This procedure has well-known complications. Ureterorenoscopic interventions can cause major or minor complications such as ureteral perforation, access problem, stone migration, urosepsis and ureteral stricture [27]. Watson et al. [28] reported a 9.7\% complication rate with bilateral URS for different etiologies in their series of 95 patients. Harmon et al. [29] observed a decrease in the complication rate from $20 \%$ to $12 \%$ during a 10 -year period. The decrease was attributed to the use of small caliber ureterorenoscopes and increased surgeon experience. In the current study, the complications were minor and were treated by conservative methods or temporary drainage with stents. No major complications were observed. Our complication rate of $12.9 \%$ is comparable with other studies that reported bilateral single-session URS for bilateral stones $[5,25,26]$. To achieve successful results with low complication rates, good visibility and careful advancement of the ureterorenoscope in the ure- ter are necessary. When we examine the complications, stone migration seems to be the major cause of the unsuccessful cases. There are various devices and modifications, including Lithocatch, Lithovac, Passport Balloon and the Dretler cone, to avoid stone migration. Currently, we have not used any of the techniques above. We are now performing the procedure with low fluid pressure and the aid of a ureteral basket.

\section{Conclusions}

Bilateral single-session URS with PL is a highly effective treatment modality for bilateral ureteral stones. The success rate of PL is affected by the stone size and location. Considering the high stone-free rates, PL can be recommended as the first-line treatment for bilateral ureteral stones in all locations.

\section{References}

1 Wirtz P, Krambeck AE, Handa SE, Terry C, Lingeman JE: Contralateral ureteroscopy performed at percutaneous nephrolithotomy: a unique evaluation of stone-free rates. J Urol 2010;184:2378-2382.

- Honeck P, Hacker A, Alken P, Michel MS, Knoll T: Shock wave lithotripsy versus ureteroscopy for distal ureteral calculi: a prospective study. Urol Res 2006;34:190-192.

3 Anagnostou T, Tolley D: Management of ureteric stones. Eur Urol 2004;45:714-721.

4 Wu CF, Shee JJ, Lin WY, Lin CL, Chen CS: Comparison between extracorporeal shock wave lithotripsy and semirigid ureterorenoscope with holmium: YAG laser lithotripsy for treating large proximal ureteral stones. J Urol 2004;172:1899-1902.

5 Camilleri JC, Schwalb DM, Eshghi M: Bilateral same session ureteroscopy. J Urol 1994; 152:49-52.

6 Dindo D, Demartines N, Clavien PA: Classification of surgical complications: a new proposal with evaluation in a cohort of a 6,336 patients and results of a survey. Ann Surg 2004;240:205-213.

7 Raman J, Bagrodia A, Gupta A, Bensalah K, Cadeddu JA, Lotan Y, Pearle MS: Natural history of residual fragments following percutaneous nephrostolithotomy. J Urol 2009; 181:1163-1168.
8 Pearle MS, Lingeman JE, Leveillee R, Kuo R, Preminger GM, Nadler RB, Macaluso J, Monga M, Kumar U, Dushinski J, Albala DM, Wolf JS Jr, Assimos D, Fabrizio M, Munch LC, Nakada SY, Auge B, Honey J, Ogan K, Pattaras J, McDougall EM, Averch TD, Turk T, Pietrow P, Watkins S: Prospective, randomized trial comparing shock wave lithotripsy and ureteroscopy for lower pole caliceal calculi $1 \mathrm{~cm}$ or less. J Urol 2008; 179(5 suppl):69-73.

9 Gunlusoy B, Degirmenci T, Arslan M, Kozacioğlu Z, Nergiz N, Minareci S, Ayder AR: Bilateral single-session ureteroscopy with pneumatic lithotripsy for bilateral ureter stones: feasible and safe. Urol Int 2008;81: 202-205.

10 Osario L, Lima E, Soares J, Autorino R, Versos R, Lhamas A, Marcelo F: Emergency ureteroscopic management of ureteral stones: Why not? Urology 2007;69:27-31.

11 Gurbuz ZG, Gonen M, Fazlıglu A, Akbulut $\mathrm{H}$ : Ureteroscopy and pneumatic lithotripsy, followed by extracorporeal shock wave lithotripsy for the treatment of distal ureteral stones. Int J Urol 2002;9:441-444.

12 Brito AH, Mitre AI, Srougi M: Ureteroscopic pneumatic lithotripsy of impacted ureteral calculi. Int Braz J Urol 2006;32:295-299.

13 Halachmi S, Nagar M, Golan S, Ginesin Y, Meretyk S: Extracorporeal shock wave lithotripsy for large ureteral stones using HM3 lithotriptor. J Urol 2006;176:1449-1452.
14 Kijuikai K, Halebian EG, Preminger MG, La Rosette J: Shock wave lithotripsy or ureteroscopy for the management of proximal ureteral calculi: an old discussion revisited. J Urol 2007;178:1157-1163.

15 Lee YH, Tsai JY, Jiaan BP, Wu T, Yu CC: Prospective randomized trial comparing shock wave lithotripsy and ureteroscopic lithotripsy for management of large upper third ureteral stones. Urology 2006;67:480-484.

16 Youssef RF, El-Nahas AR, El-Assmy AM, ElTabey NA, El-Hefnawy AS, Eraky I, El-Kenawy MR, El-Kappany HA, Sheir KZ: Shock wave lithotripsy versus semirigid ureteroscopy for proximal ureteral calculi $(<20 \mathrm{~mm})$ : a comparative matched-pair study. Urology 2009;73:1184-1187.

17 Ather MH, Nazim SM, Sulaiman MN: Efficacy of semirigid ureteroscopy with pneumatic lithotripsy for ureteral stone surface area of greater than $30 \mathrm{~mm}^{2}$. J Endourol 2009;23:619-622.

18 Kravchick S, Bunkin I, Stepnov E, Peled R, Agulansky L, Cytron S: Emergency extracorporeal shockwave lithotripsy for acute renal colic caused by upper urinary tract stones. J Endourol 2005;19:1-4.

19 Gunlusoy B, Degirmenci T, Arslan M, Kozacioglu Z, Nergiz N, Minareci S, Ayder AR: Ureteroscopic pneumatic lithotripsy: is location of the stone important in decision making? J Endourol 2008;22:291-294. 
-20 Chan VO, Buckley O, Persaud T, Torreggiani WC: Urolithiasis: how accurate are plain radiographs? Can Assoc Radiol J 2008;59:131134.

-21 Johnston R, Lin A, Du J, Mark S: Comparison of kidney-ureter-bladder abdominal radiography and computed tomography scout films for identifying renal calculi. BJU Int 2009; 104:670-673.

22 Dixon AK, Dendy P: Spiral CT: how much does radiation dose matter? Lancet 1998;352: 1082-1083.
23 Schatloff O, Lindner U, Ramon J, Winkler HZ: Randomized trial of stone fragment active retrieval versus spontaneous passage during holmium laser lithotripsy for ureteral stones. J Urol 2010;183:1031-1036.

24 Teichman JM, Vassar GJ, Bishoff JT, Bellman GC: Holmium:YAG lithotripsy yields smaller fragments than lithoclast, pulsed dye laser or electrohydraulic lithotripsy. J Urol 1998; 159:17-23.

25 Hollenbeck BK, Schuster TG, Faerber GJ, Wolf JS: Safety and efficacy of same-session bilateral ureteroscopy. J Endourol 2003;17: 881-885.

26 Deliveliotis C, Picramenos D, Alexopoulou K, Christofis I, Kostakopoulos A, Dimopoulos C: One-session bilateral ureteroscopy: is it safe in selected patients? Int Urol Nephrol 1996;28:481-484.
27 Parker BD, Frederick RW, Reilly TP, Lowry PS, Bird ET: Efficiency and cost of treating proximal ureteral stones: shock wave lithotripsy versus ureteroscopy plus holmium:yttriumaluminum-garnet laser. Urology 2004;64: 1102-1106.

28 Watson JM, Chang C, Pattaras JG, Ogan K: Same session bilateral ureteroscopy is safe and efficacious. J Urol 2011;185:170-174.

29 Harmon WJ, Sershon PD, Blute ML, Patterson DE, Segura JW: Ureteroscopy: current practice and long-term complications. J Urol 1997;157:28-32. 